\title{
A Study on the Variations in the Formation of the Trunks of Brachial Plexus
}

\author{
Estudio sobre las Variaciones en la Formación de los Troncos del Plexo Braquial
}

"Surekha D. Shetty; "Satheesha Nayak B; *Venu Madahv; "* Cilwyn Shalitha Braganza \& *S. N. Somayaji

SHETTY, S. D.; NAYAK, B. S.; MADAHV, V.; BRAGANZA, C. S. \& SOMAYAJI, S. N. A study on the variations in the formation of the trunks of brachial plexus. Int. J. Morphol., 29(2):555-558, 2011.

SUMMARY: Brachial plexus shows several variations in its formation and branching pattern. Variations in the formation of the trunks are very rare. We studied 44 dissected specimens specifically for variations in the formation of the trunks of the brachial plexus. 5 cadavers $(11.3 \%)$ showed variations in the formation of the trunks. All the variations were unilateral. In one cadaver (2.27\%), the middle trunk was formed by union of $\mathrm{C} 7$ and $\mathrm{C} 8$ roots and lower trunk was formed by $\mathrm{T} 1$ root. Upper and middle trunks were fused with each other in one specimen (2.27\%). In 3 specimen (6.81\%), the C5 root pierced scalenus anterior before joining C6 to form the upper trunk. Knowledge of its variations is of importance to orthopedic surgeons, neurologists and anesthesiologists.

KEY WORDS: Brachial plexus; Variation; Nerve; Trunks; Roots; Neck.

\section{INTRODUCTION}

Brachial plexus is the plexus of nerves situated partly in the posterior triangle of the neck (supraclavicular part) and partly in the axilla (infraclavicular part). It is formed by the ventral primary rami of $\mathrm{C} 5, \mathrm{C} 6, \mathrm{C} 7, \mathrm{C} 8$ and part of $\mathrm{T} 1$ spinal nerves. The upper trunk of the plexus is formed by the union of $\mathrm{C} 5$ and $\mathrm{C} 6$ roots; middle trunk is formed by the C7 root and the lower trunk is formed by the union of C8 and $\mathrm{T} 1$ roots. Each trunk divides into ventral and dorsal divisions. The ventral divisions of upper and middle trunks join to form the lateral cord; the ventral division of the lower trunk continues as the medial cord and the posterior divisions of all three trunks join to form the posterior cord of the brachial plexus. The lateral cord gives 3 branches i.e. lateral root of the median nerve, lateral pectoral nerve and the musculocutaneous nerve. The medial cord gives 5 branches i.e. medial cutaneous nerve of the arm, medial cutaneous nerve of the forearm, medial pectoral nerve, medial root of the median nerve and ulnar nerve. The posterior cord gives 5 branches i.e. upper subscapular nerve, lower subscapular nerve, thoracodorsal nerve, axillary nerve and radial nerve. The roots and trunks of the brachial plexus are sandwiched between the scalenus anterior and medius muscles. The cords and the branches are situated in the axilla.

Several variations exist in the roots, trunks, cords and branches of the brachial plexus. In this study we concentrated on the variations of the formation of the trunks of the brachial plexus and their relation to the scalene muscles.

\section{MATERIAL AND METHOD}

We observed 44 dissected head and neck specimens stored in 10 percent formalin for variations in the formation of the trunks of the brachial plexus. The scalene muscles, the roots, trunks and the divisions of the trunks were cleaned. The contribution for the formation of the trunks; the pattern of the division of the trunks and their relationship with the scalene muscles were noted. Variations found were photographed. The study was conducted at Melaka Manipal Medical College (Manipal Campus) Manipal University, India.

\section{RESULTS}

Among the 44 specimens observed, 5 cadavers $(11.3 \%)$ showed variations in the formation of the trunks. All the variations were unilateral. In one cadaver $(2.27 \%)$, the middle trunk was formed by union of $\mathrm{C} 7$ and $\mathrm{C} 8$ roots

\footnotetext{
* Department of Anatomy, Melaka Manipal Medical College (Manipal Campus) Manipal University, Manipal, India.

** Department of Anatomy, KMC International Center, Manipal Univeristy, Manipal. India.
} 
and lower trunk was formed by only $\mathrm{T} 1$ root (Fig. 2). Upper and middle trunks were fused with each other (Fig. 3) in one specimen (2.27\%). In 3 specimen (6.81\%), the C5 root pierced scalenus anterior before joining $\mathrm{C} 6$ to form the upper trunk (Fig. 4).

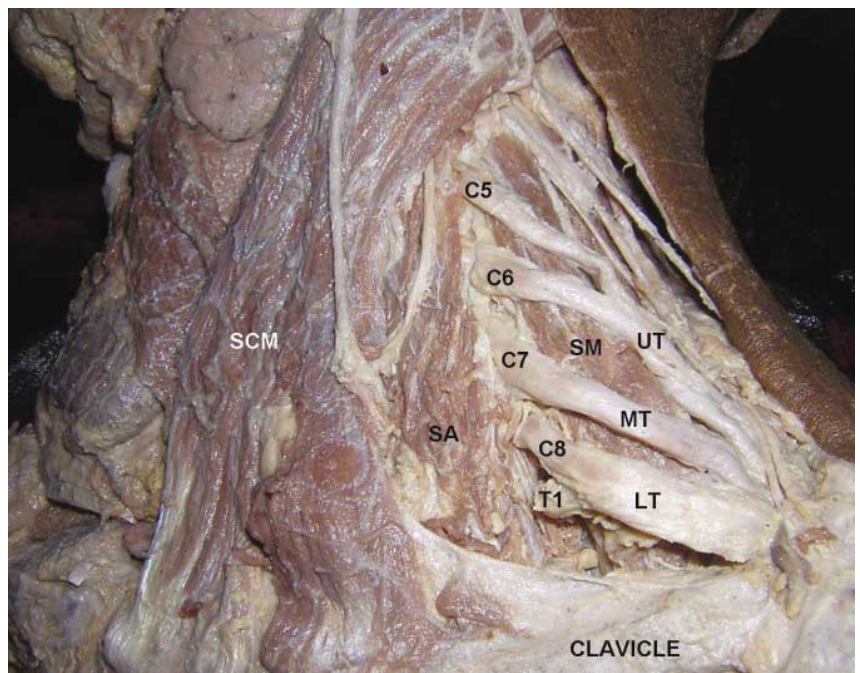

Fig. 1. Dissection of the roots and trunks of left brachial plexus (C5, C6, C7, C8 and T1 - roots of brachial plexus; UT - upper trunk; MT - middle trunk; LT - lower trunk; SA - scalenus anterior; SM scalenus medius; SCM - sternocleidomastoid).

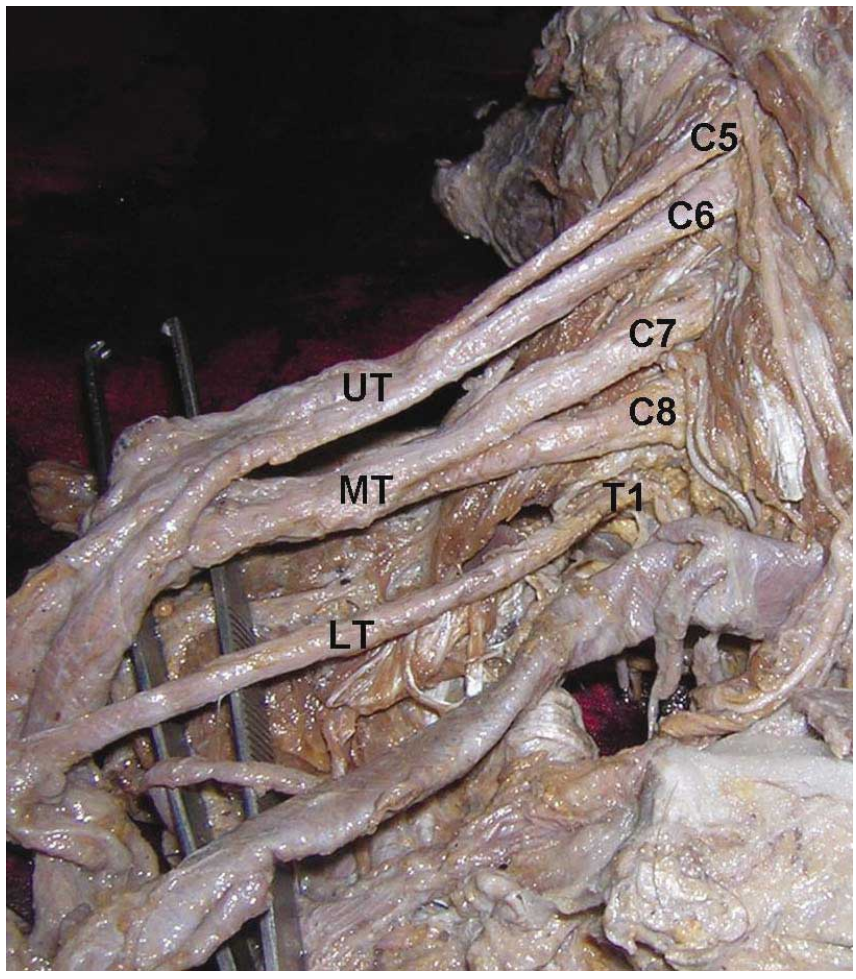

Fig. 2. Dissection of the roots and trunks of right brachial plexus (C5, C6, C7, C8 and T1 - roots of brachial plexus; UT - upper trunk; MT - middle trunk; LT - lower trunk).

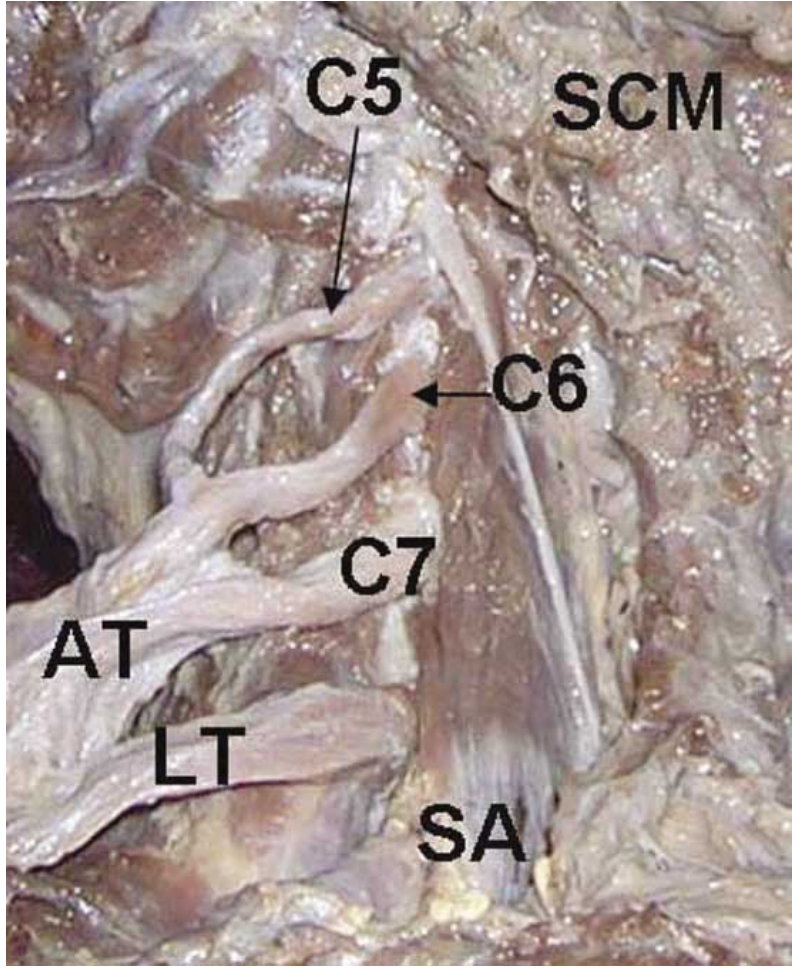

Fig. 3. Dissection of the roots and trunks of right brachial plexus (C5, C6, C7- roots of brachial plexus; AT - abnormal trunk formed by fusion of upper and middle trunks; LT - lower trunk; $\mathrm{SA}$ - scalenus anterior; SCM - sternocleidomastoid).

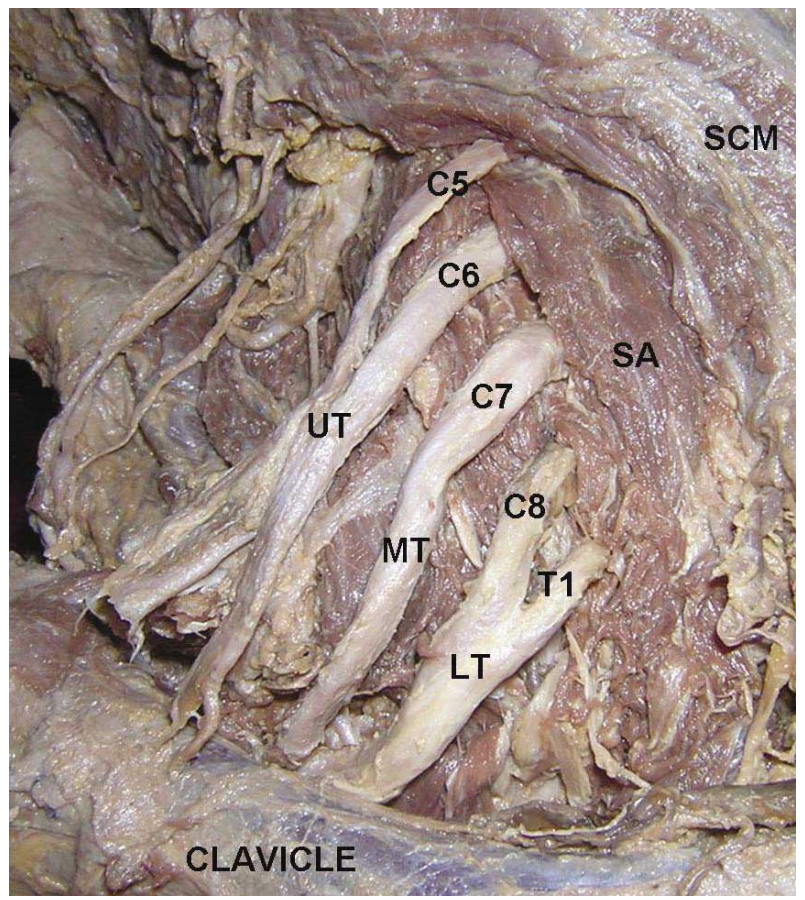

Fig. 4. Dissection of the roots and trunks of right brachial plexus (C5, C6, C7, C8 and T1 - roots of brachial plexus; UT - upper trunk; MT - middle trunk; LT - lower trunk; SA - scalenus anterior; SCM - sternocleidomastoid). 


\section{DISCUSSION}

The brachial plexus variations could fail the brachial plexus loco-regional anesthesia. In the surgical treatment of brachial plexus lesions, the surgeon must know brachial plexus anatomical variations perfectly. Common variations in the formation, prefixed and postfixed plexuses have been well documented (Matejcik, 2003a, 2003b, 2005; Lee et al., 1992). Variations in the formation of the trunks of the brachial plexuses have also been reported (Matejcik, 2003b).

In a study by Uysal et al. (2003) the superior trunk was not formed in $1 \%$ of cases, inferior trunk was not formed in $9 \%$ of cases. They also reported the formation of superior trunk by $\mathrm{C} 4$ and $\mathrm{C} 5$ roots and formation of inferior trunk by $\mathrm{T} 1$ and $\mathrm{T} 2$ roots (Uysal et al.). Formation of upper trunk of brachial plexus by $\mathrm{C} 5, \mathrm{C} 6$ and $\mathrm{C} 7$ roots is very rare. This will be associated with absence of the middle trunk. We can also interpret this as anatomical fusion of upper and middle trunks. One such abnormal upper trunk has been reported by Nayak et al. (2005). Matejcik (2003a) has reported a bilateral case of fusion of upper and middle trunks.

In our study we saw a variation in the formation of middle trunk. The middle trunk was formed by the union of $\mathrm{C} 7$ and $\mathrm{C} 8$ roots in one cadaver. A variation similar to this has not been reported yet.
The C5 root pierced the scalenus anterior muscle in $3(6.81 \%)$ of cases. The root may get entrapped if the scalenus muscle gets hypertrophied. This may lead to muscle weakness and sensory alteration in the areas supplied by the fibres of this root.

In the previous studies, the variations in the brachial plexus were more frequent in the left side (Matejcik, 2003b) but in our case, most of the variations found were on the right side.

The knowledge of variations in the formation of brachial plexus is very useful for neurosurgeons. It will be of great use in the surgical treatment of tumors of nerve sheaths such as schwannomas and neurofibromas. The awareness of the variations might also help in treating the non-neural tumors like lipoma. Orthopedic procedures of the cervical spine also need a thorough knowledge of the normal and abnormal formation of brachial plexus. Since the roots and trunks of brachial plexus show variations, and the variations can be found by ultrasound examinations, it is better to look for variations before planning the surgery in this area (Royse et al., 2006). Though the variation of the brachial plexus may not alter the normal functioning of the limb of the person, it is very important in clinical neurosurgery and orthopedic procedures.

SHETTY, S. D.; NAYAK, B. S.; MADAHV, V.; BRAGANZA, C. S. \& SOMAYAJI, S. N. Estudio sobre las variaciones en la formación de los troncos del plexo braquial. Int. J. Morphol., 29(2):555-558, 2011.

RESUMEN: EL plexo braquial muestra algunas variaciones en su formación y patrón de ramificación. Las variaciones en la formación de los troncos son muy raras. Se disecaron 44 especímenes para observar las eventuales variaciones en la formación de los troncos del plexo braquial. Cinco cadáveres $(11,3 \%)$ mostraron variaciones en la formación de los troncos. Todas las variaciones fueron unilaterales. En un cadáver (2,27\%), el tronco medio se formó por la unión de las raíces C7 y C8 y, parte inferior del tronco, estaba formado por la raíz de T1. En un caso (2,27\%) los troncos superior y medio se fusionaron entre sí. En 3 muestras $(6,81 \%)$, la raíz de C5 cruzó el músculo escaleno anterior antes de unirse a C6 para formar la parte superior del tronco. El conocimiento de estas variaciones es importante para los cirujanos ortopédicos, los neurólogos y anestesiólogos.

PALABRAS CLAVE: Plexo braquial; Variación; Nervios; Troncos; Raíces; Cuello.

\section{REFERENCES}

Lee, H. Y.; Chung, I. H.; Sir, W. S.; Kang, H. S.; Lee, H. S.; Ko, J. S.; Lee, M. S. \& Park, S. S. Variations of the ventral rami of the brachial plexus. J. Korean Med. Sci., 7(1):19-24, 1992.

Matejcik, V. Aberrant formation and clinical picture of brachial plexus from the point of view of a neurosurgeon. Bratisl. Lek. Listy, 104(10):291-9, 2003.

Matejcik, V. Anatomic variations in the brachial plexus trunks and nerve roots. Rozhl. Chir., 82(9):456-9, 2003. 
SHETTY, S. D.; NAYAK, B. S.; MADAHV, V.; BRAGANZA, C. S. \& SOMAYAJI, S. N. A study on the variations in the formation of the trunks of brachial plexus. Int. J. Morphol., 29(2):555-558, 2011.

Matejcik, V. Variations of nerve roots of the brachial plexus. Bratisl. Lek. Listy, 106(1):34-6, 2005.

Royse, C. E.; Sha, S.; Soeding, P. F. \& Royse, A. G. Anatomical study of the brachial plexus using surface ultrasound. Anaesth. Intensive Care, 34(2):203-10, 2006.

Nayak, S.; Somayaji, N; Vollala, V. R.; Raghunathan, D.; Rodrigues, V.; Samuel, V. P. \& Alathady Malloor, P. A rare variation in the formation of the upper trunk of the brachial plexus - a case report. Neuroanatomy, 4(1):378, 2005.

Uysal, I. I.; Seker, M.; Karabulut, A. K.; Büyükmumcu, M. \& Ziylan, T. Brachial plexus variations in human fetuses. Neurosurgery, 53(3):676-84, 2003.
Correspondence to: Dr. Satheesha Nayak B. Professor of Anatomy Melaka Manipal Medical College (Manipal Campus) Madhav Nagar, Manipal Udupi District Karnataka State, 576104. INDIA

Phone: +91 820 2922519, +919844009059

Email: nayaksathish@yahoo.com

Received: 17-02-2010

Accepted: 22-02-2011 